\title{
Isoreticular Three-Dimensional Kagome Metal-Organic Frameworks with Open-Nitrogen-Donor Pillars for Selective Gas Adsorption
}

Andy Dinh, ${ }^{+}$Huajun Yang, ${ }^{\dagger}$ Fang Peng, ${ }^{+}$Tony $C$. Nguyen, ${ }^{\dagger}$ Anh Hong, ${ }^{\ddagger}$ Pingyun Feng, ${ }^{\ddagger}$ and Xianhui Bu ${ }^{*}+$

$\dagger$ Department of Chemistry and Biochemistry, California State University, Long Beach, California 90840, United States.

¥ Department of Chemistry, University of California, Riverside, California 92521, United States. 
(a)<smiles>O=C(O)c1ccc(C(=O)O)o1</smiles><smiles>[Z7]OC(=O)c1ccc(C(=O)O[Ga])o1</smiles>

(d)

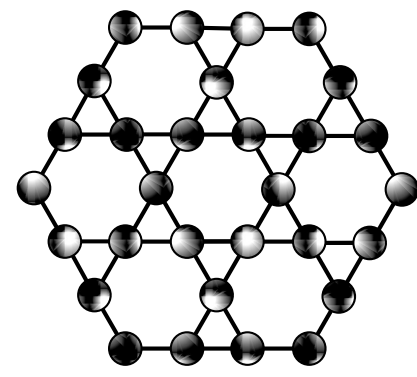

2D Latticec (KGM net) (b)

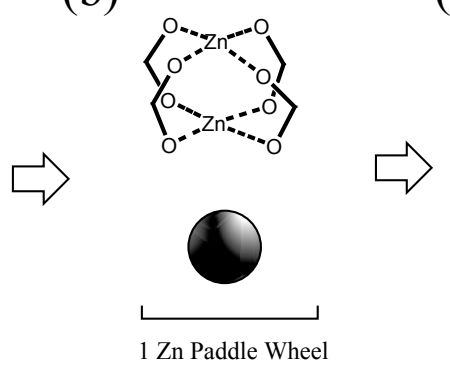

(e)

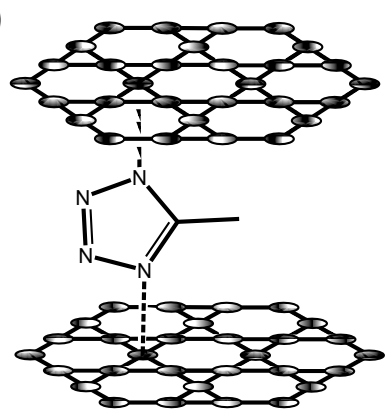

Kagome Nets Pillared by MTZ

(c)

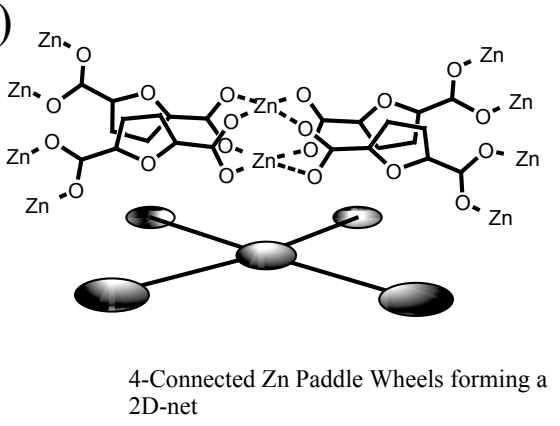

(f)

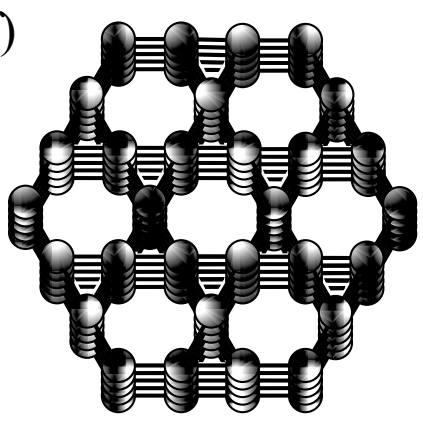

3D Lattice (KAG Topology)

Scheme S1. Structural evolution of CPM-63m: (a) Bonding mode of FDC; (b) Zn dimer coordinated by 4 carboxylate groups, forming the $\mathrm{Zn}$ paddlewheel; (c) Connectivity of each $\mathrm{Zn}$ paddlewheel to four other $\mathrm{Zn}$ paddlewheels with FDC; (d) 2D KGM lattice formed from Zn paddlewheel and FDC; (e) MTZ as a pillar connecting the KGM layers; (f) 3D lattice with kag topology. 

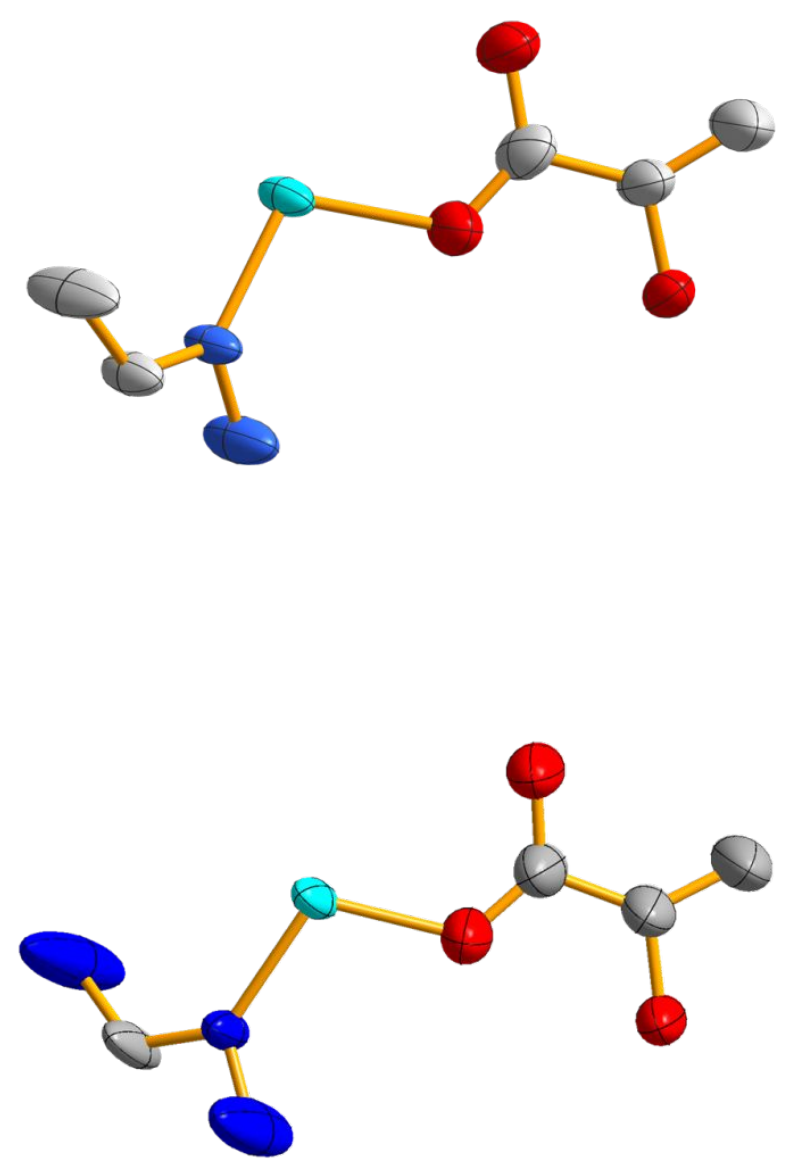

Figure S1. Asymmetric unit of CPM-63m (top) and CPM-63a (bottom). Atoms are shown with $50 \%$ probability. Zn: turquoise; $\mathrm{C}$ : grey; N: blue; O: red. Hydrogen atoms are deleted for clarity. 

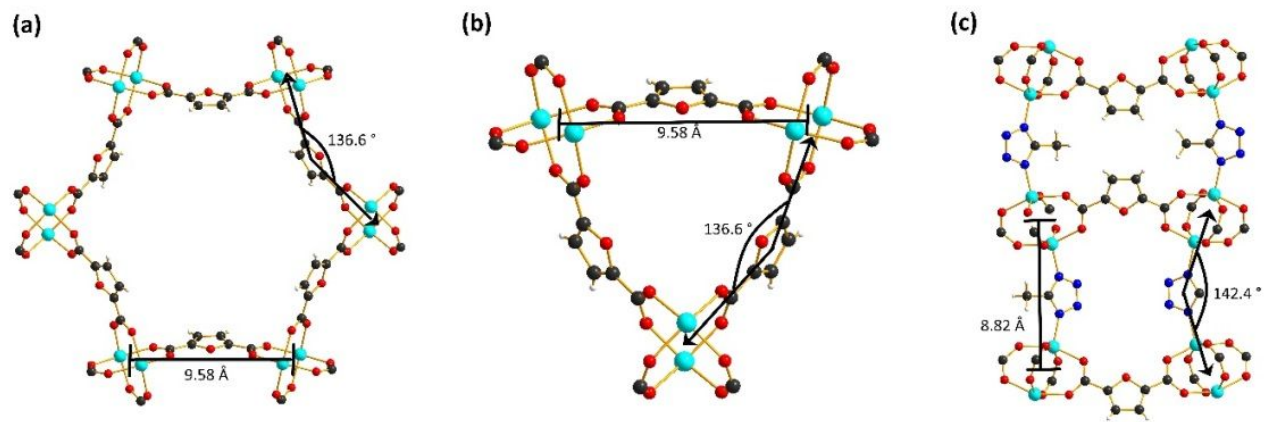

Figure S2. Dimer-to-dimer distance and ligand's angle for (a) hexagonal (b) trigonal and (c) square windows 

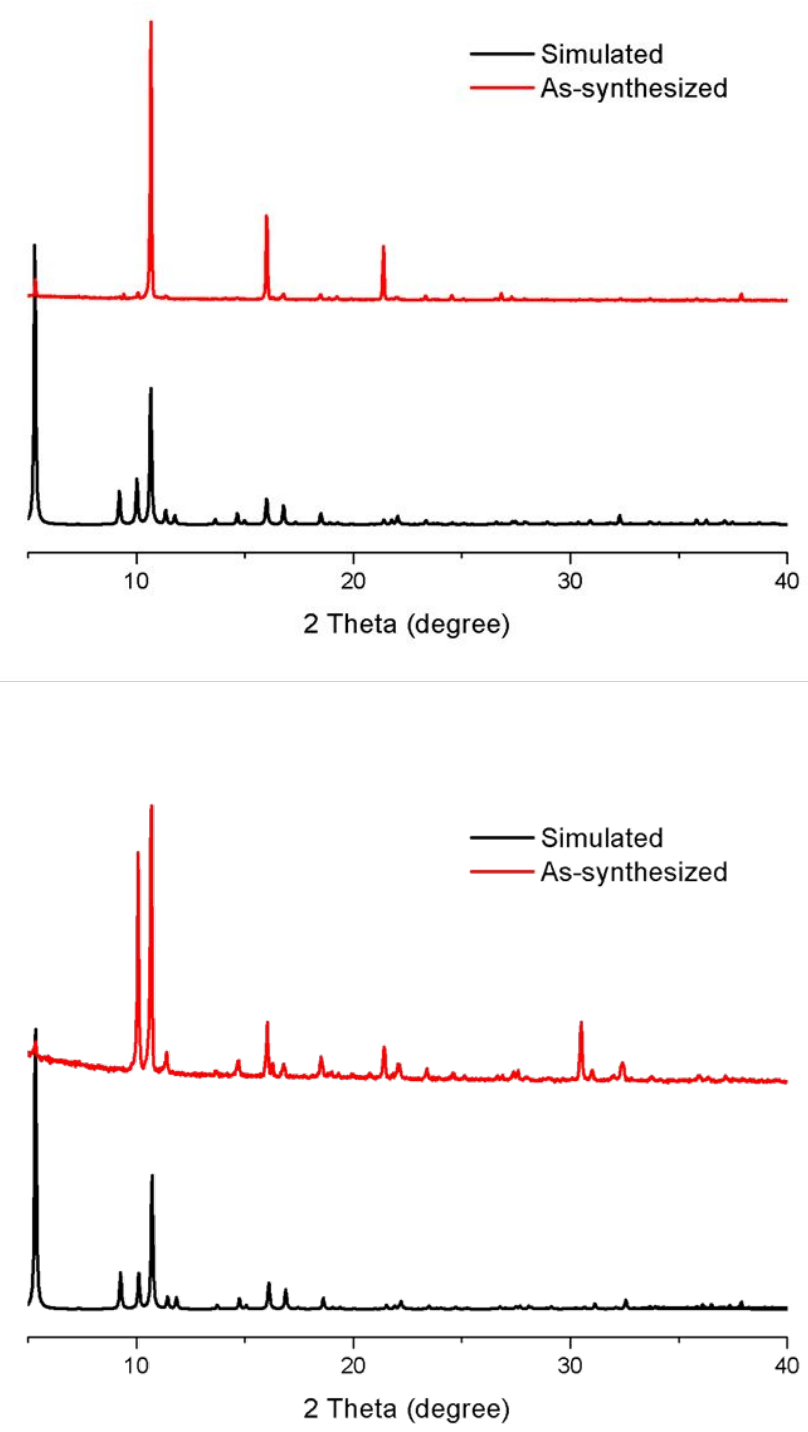

Figure S3. Powder X-Ray Diffraction pattern of the synthesized CPM-63m (top) and CPM-63a (bottom) compared with simulated pattern taken from single crystal data. 


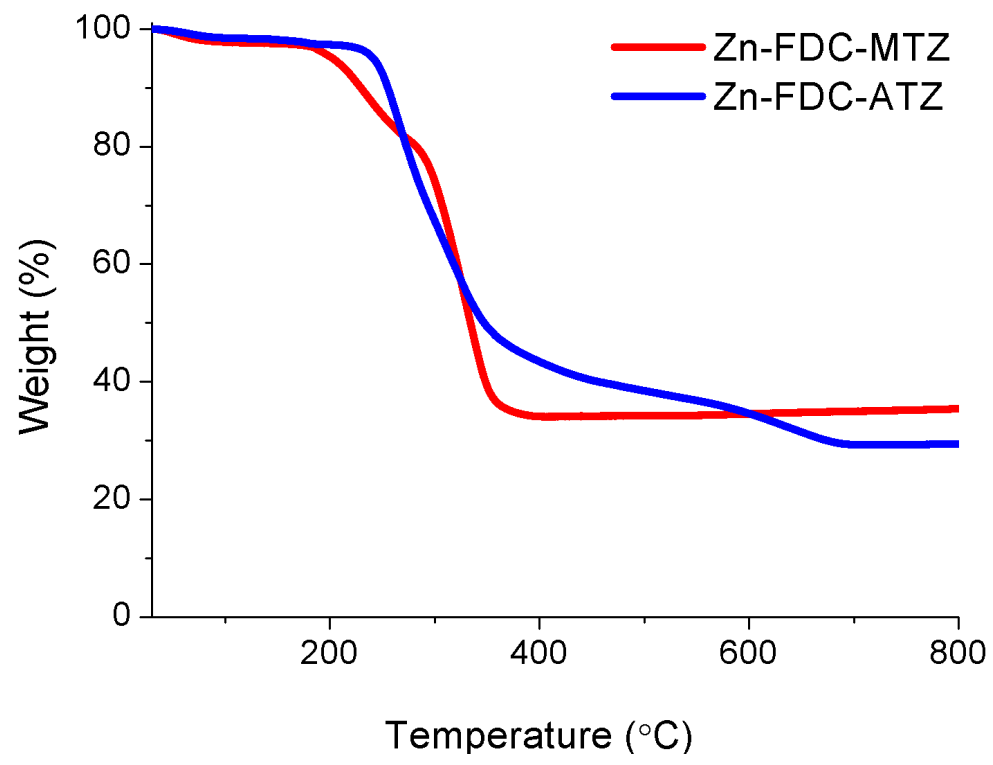

Figure S4. TGA traces for activated CMP-63m and CPM-63a. 


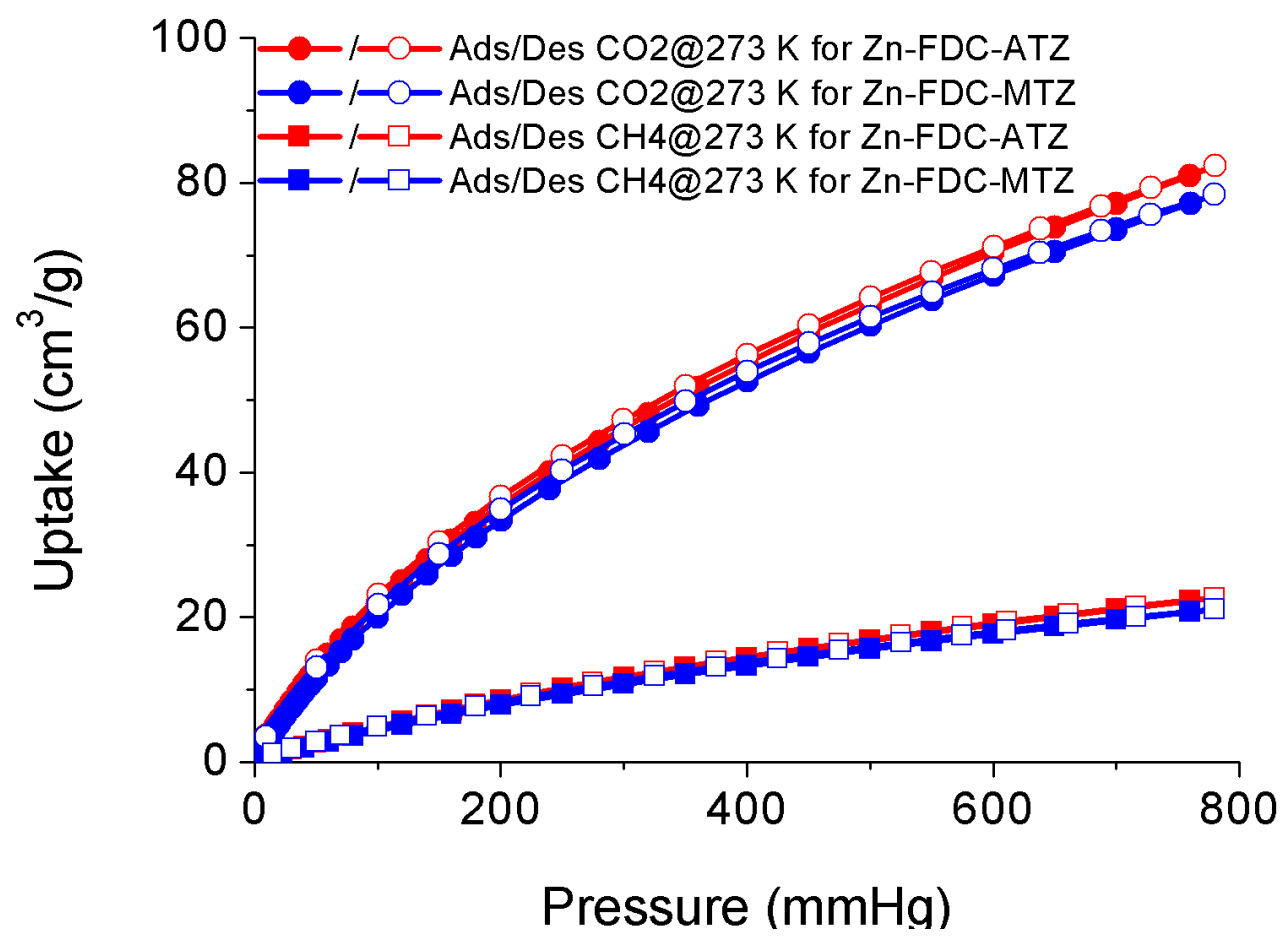

Figure S5. $\mathrm{CO}_{2}$ and $\mathrm{CH}_{4}$ adsorption at $273 \mathrm{~K}$ for CPM-63m and CPM-63a. 

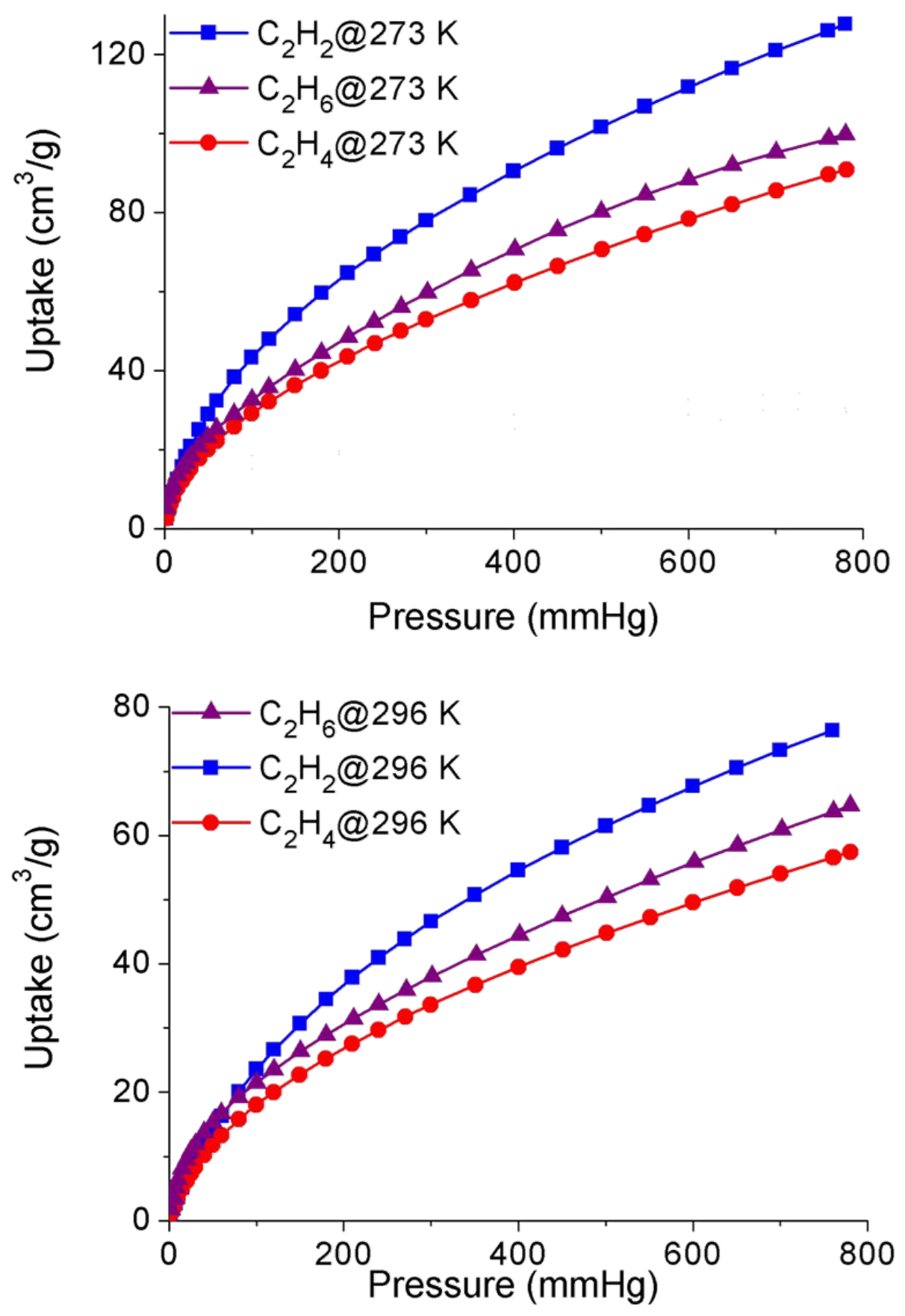

Figure S6. $\mathrm{C}_{2} \mathrm{H}_{2}, \mathrm{C}_{2} \mathrm{H}_{4}$ and $\mathrm{C}_{2} \mathrm{H}_{6}$ adsorption isotherms of CPM-63m at 273 K(top) and $296 \mathrm{~K}$ (bottom). 

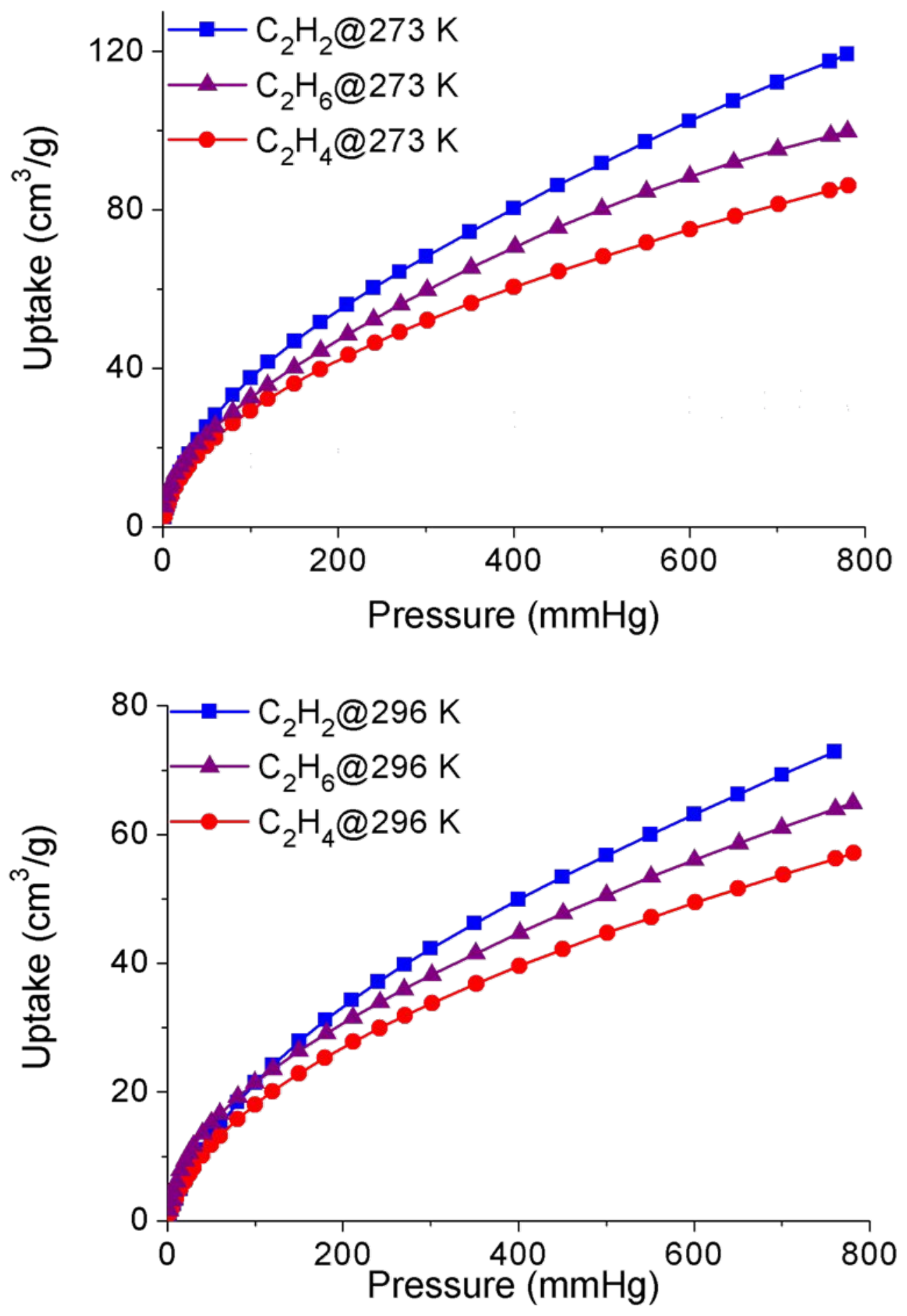

Figure S7. $\mathrm{C}_{2} \mathrm{H}_{2}, \mathrm{C}_{2} \mathrm{H}_{4}$ and $\mathrm{C}_{2} \mathrm{H}_{6}$ adsorption isotherms of CPM-63a at $273 \mathrm{~K}$ (top) and 296 K(bottom). 


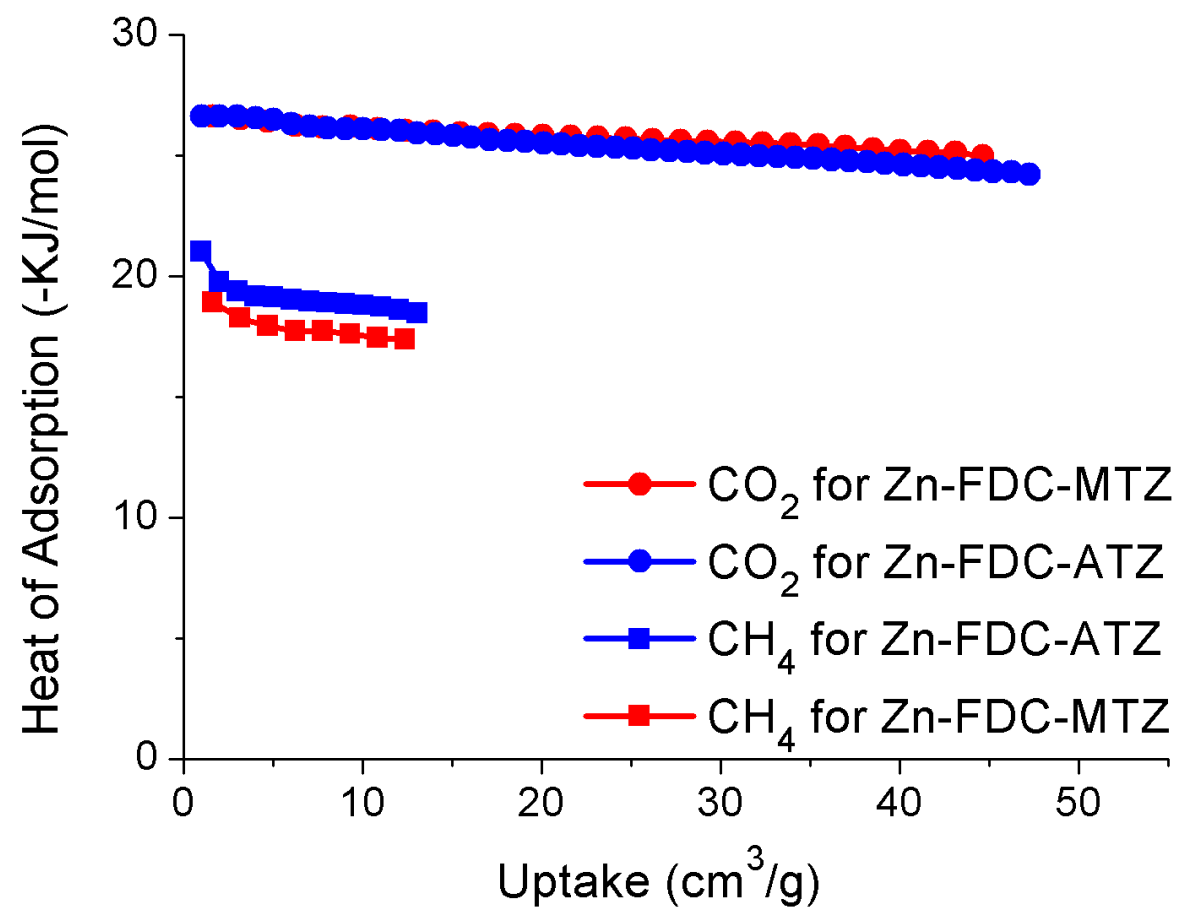

Figure S8. Heat of adsorptions of $\mathrm{CO}_{2}$ and $\mathrm{CH}_{4}$ for CPM-63m and CPM-63a. 


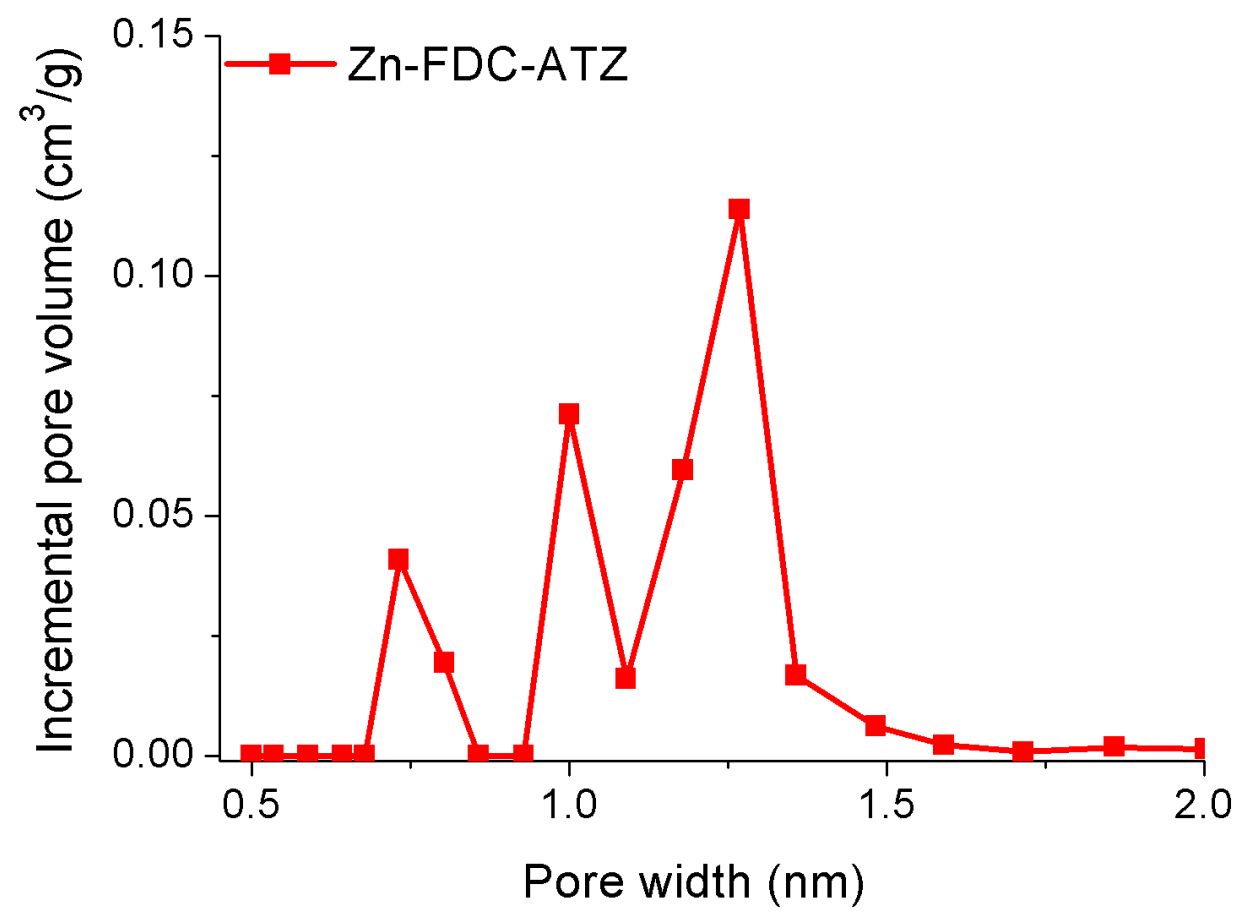

Figure S9. DFT pore size distribution of CPM-63a. 

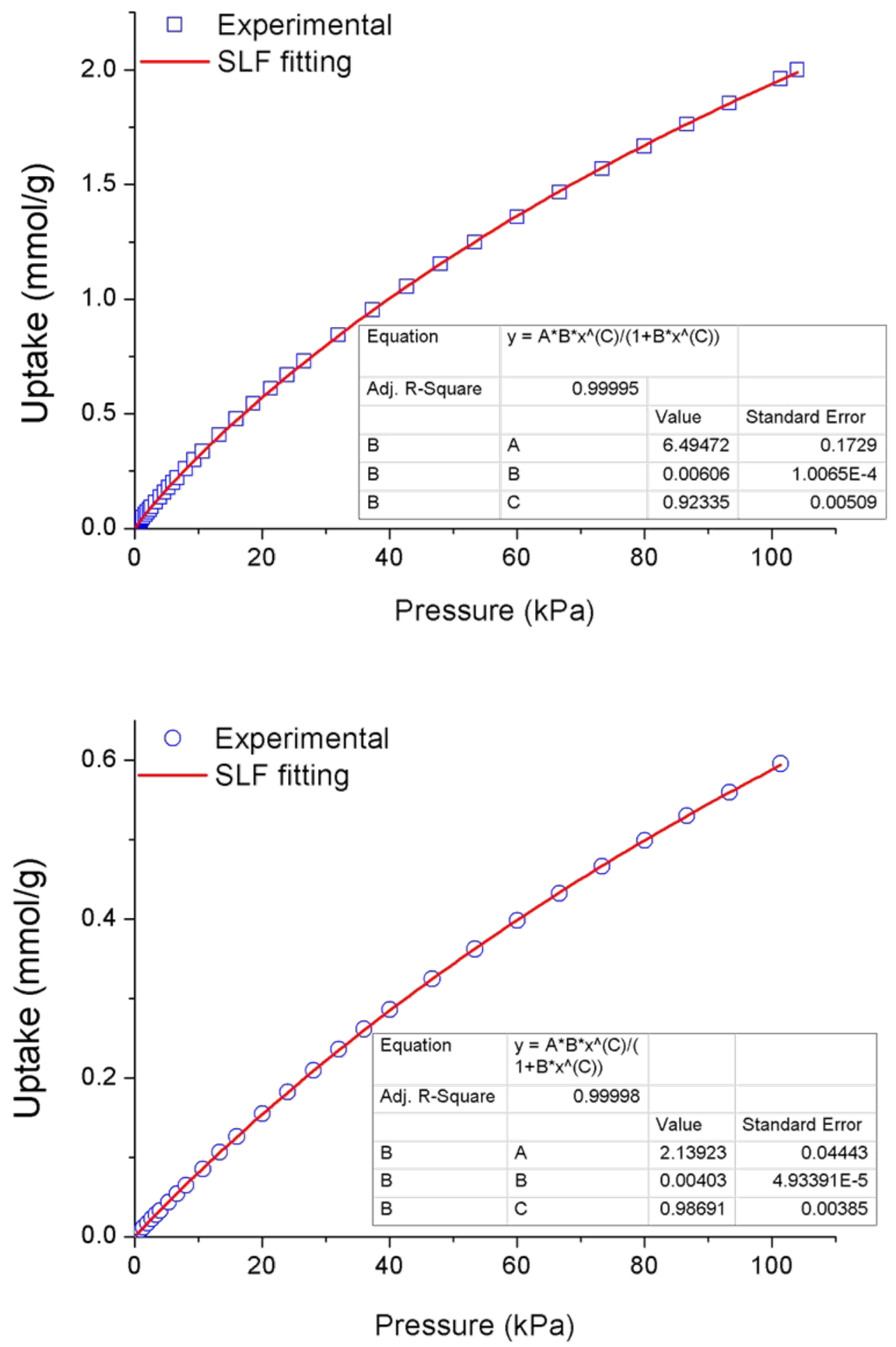

Figure S10. SLF fitting of $\mathrm{CO}_{2}$ (top) and $\mathrm{CH}_{4}$ (bottom) adsorption isotherms for CPM-63m. 

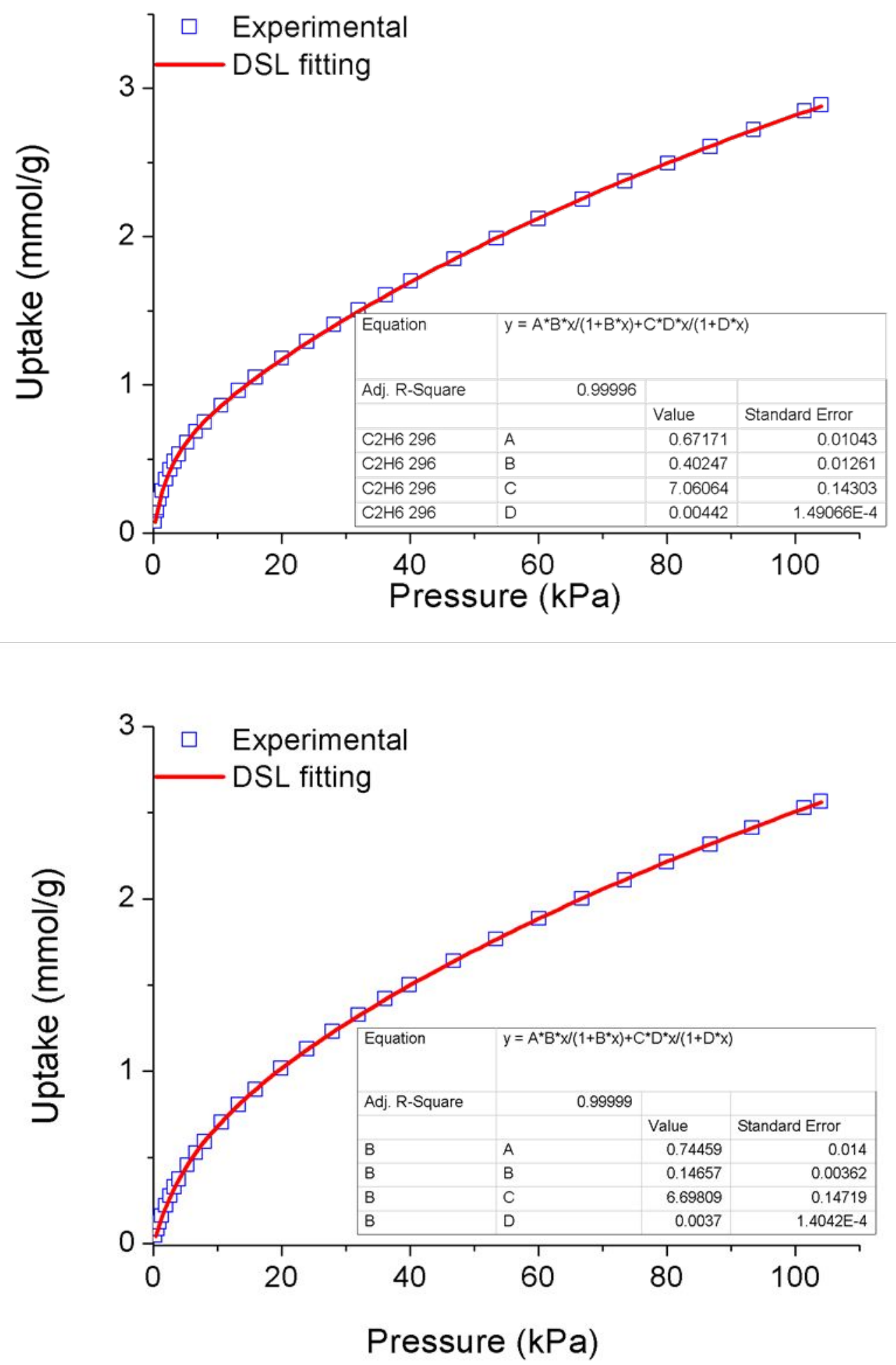

Figure S11. DSL fitting of $\mathrm{C}_{2} \mathrm{H}_{6}$ (top) and $\mathrm{C}_{2} \mathrm{H}_{4}$ (bottom) adsorption isotherms for CPM-63m. 